\title{
The Recent Management and Treatment of COVID-19 Novel Corona Virus "Better use of Science, Better Treatment for COVID-19 Patients"
}

\author{
Ahsan Ali Siddiqui*, MD, MSPH, UK \\ Consultant Public Health, Quality Management \& Patient Safety Department, General Directorate of Health, Saudi Arabia
}

\begin{abstract}
Background and Objective: The main Aim of this article is to highlight the latest Prevention, Treatment and Vaccine development of COVID-19 recently in Mid-2020. Currently there is no proven treatment of COVID-19 and still no Vaccine available for public. Some of the Antiviral drugs has shown promising results in treatment but more Scientific, Medical research is needed to find the Treatment as earliest as possible.

Methods: The author of this article has done literature review, comparison and critical analysis of more than 20 Published articles and other reviews. Author has chosen the Comparative Literature review as methodology for this research article. The purpose is to show that Randomly chosen articles are in favor of availability of prevention, treatment and vaccine development of COVID-19 as soon as possible to Treat the ill. SPSS 19 software is used to show Diagrammatic presentation for the results and analysis.
\end{abstract}

Results: The SPSS Diagrammatic Presentation shows that firstly 13 Articles agreed 100\% and 2 Articles did not, that there is urgent need of better Management and Treatment of COVID-19 novel corona virus. Second SPSS Diagram shows that All 15 Articles Favors the Importance of Urgent Recent Management and Treatment, Vaccine for the COVID-19 novel corona virus. There are some pictures, CT Scans and names of the Medicines involves in the Latest Treatment of the COVID-19 included in this Article.

Conclusion: Current Pandemic of COVID-19 has taught all the Global Health authorities such as WHO, UN, UNESCO, UNICEF, UNHCR, EU Others and all Governments of 200 countries that we were not ready for COVID-19. Although Developed Countries such as USA, UK, France and countries of EU spends Billions of US Dollars on their Health System but it did not stop the Deaths of COVID-19 Pandemic in their countries and they are actually affected the most in this world. The reason is, there is no current Vaccine, proven Treatment for COVID-19 to this date and still research is going on to find the right Treatment or Vaccine for COVID-19. More hard work needed in Medical Sciences to find out the Proven and approved vaccine and treatment for current pandemic or for preparation for Future Epidemics.

KEYWORDS: Covid-19; Sars-CoV-2; Antiviral; Chloroquine; Hydroxychloroquine; Lopinavir/Ritonavir; Favipiravir; Remdesivir; Nitazoxanide; Ivermectin; Cytokines, Immunomodulation; Melatonin; Oxidation-reduction; IL-6; Inflammatory storm, Tocilizumab; Docking; Nucleotide inhibitors; RdRp; Sofosbuvir; Structural bioinformatics; Wuhan coronavirus

Quick Response Code:

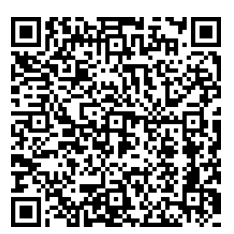

Address for correspondence: Ahsan Ali Siddiqui, MD, MSPH, UK, Consultant Public Health, Quality Management \& Patient Safety Department, General Directorate of Health, Saudi Arabia

Received: June 04, 2020 Published: June 16, 2020

How to cite this article: Ahsan Ali Siddiqui, MD, MSPH, UK. The Recent Management and Treatment of COVID-19 Novel Corona Virus "Better use of Science, Better Treatment for COVID-19 Patients”. 2020 - 2(3) OAJBS.ID.000181. DOI: 10.38125/OAJBS.000181 


\section{INTRODUCTION}

There have been more than Serap [1] 300 clinical trials going on various antiviral and immunomodulating agents are in various stages of evaluation for COVID-19 in those trials and some of them will be published in the next couple of months. Despite the urgent need to find an effective antiviral treatment for COVID-19 through randomized controlled studies certain agents are being used all over the world based on either in-vitro or extrapolated evidence or observational studies. The most frequently used agents both in Turkey and all over the world including chloroquine hydroxychloroquine lopinavir/ritonavir favipiravir and remdesivir will be reviewed here. Nitazoxanide and ivermectin were also included in this review as they have recently been reported to have an activity against SARS-CoV-2 in vitro and are licensed for the Serap [1] treatment of some other human infections.

Since the outbreak Jeroen [2] of COVID-19 chloroquine has been mentioned as a possible treatment. In vitro studies have shown anti-viral activity of chloroquine against SARS-CoV-2. Recently the Dutch National Institute for Public Health and the Environment published treatment options for antiviral treatment for COVID-19 where chloroquine was suggested as first choice for off-label treatment Jeroen [2] beside remdesivir, lopinavir/ritonavir.
Melatonin a well-known Rui [3] anti-inflammatory and antioxidative molecule is protective against ALI/ARDS caused by viral and other pathogens. Melatonin is effective in critical care patients by reducing vessel permeability anxiety sedation use and improving sleeping quality which might also be beneficial for better clinical outcomes for COVID-19 patients. Notably melatonin has a high safety profile. There is significant data showing that melatonin limits virus-related diseases and would also likely Rui [3] be beneficial in COVID-19 patients.

The biopsy samples analysis Binqing [4] at autopsy of COVID-19 Victim suggested that increased alveolar exudate caused by aberrant host immune response and inflammatory cytokine storm probably impedes alveolar gas exchange and contributes to the high mortality of severe COVID-19 patients. Our research has identified that pathogenic $\mathrm{T}$ cells and inflammatory monocytes incite inflammatory storm with large amount of interleukin 6 therefore monoclonal antibody that targets the IL- 6 pathways may potentially curb inflammatory storm. Moreover, Tocilizumab treatment that blocking IL-6 receptors showed inspiring clinical results including temperature returned to normal quickly and respiratory function improved. Therefore, we suggest that Tocilizumab is an effective treatment in severe patients of COVID-19 Binqing [4] to calm the inflammatory storm and reduce mortality.

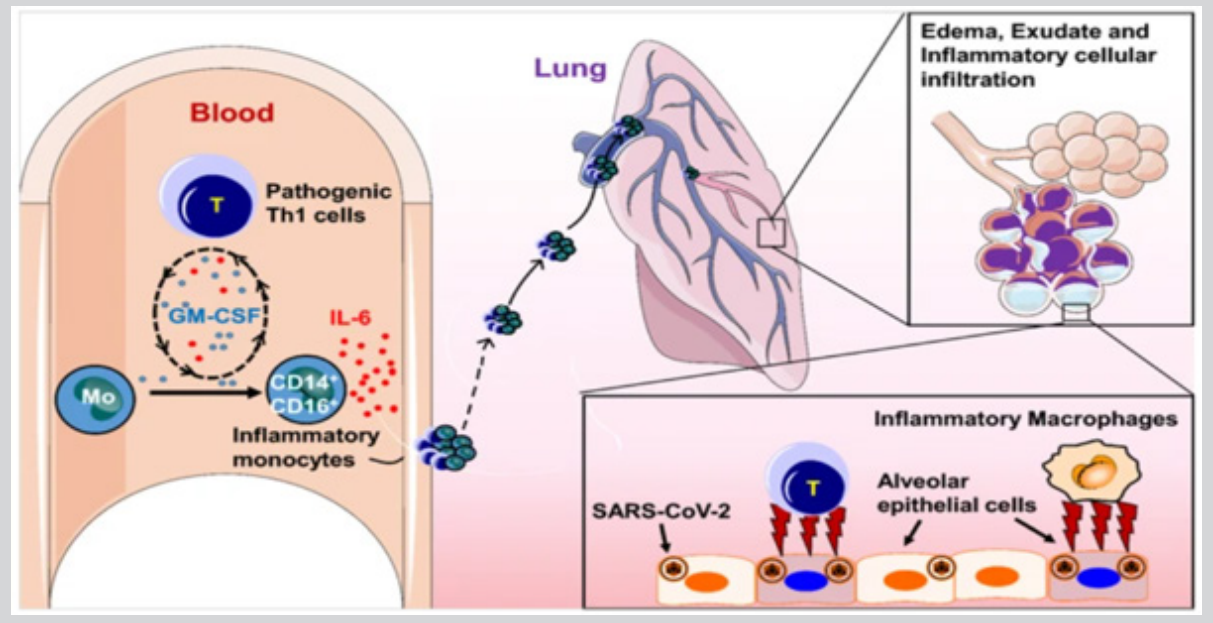

Figure 1: Binqing [4].

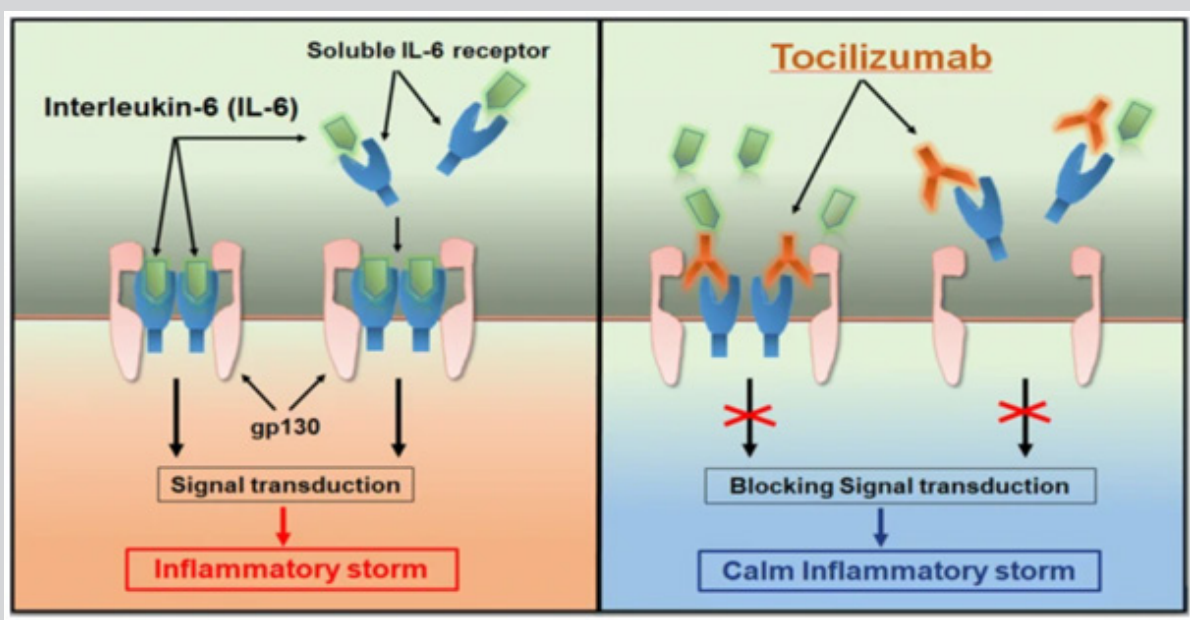

Figure 2: Binqing [4]. 
Current Pandemic AA Siddiqui [5] of COVID-19 has taught us that we in the twenty first century is not ready to provide health care to vulnerable community such as elders children and sick people with chronic illness. Such vulnerable people with bad health and low socio-economic status are more prone to get effected by COVID-19 novel corona virus. More serious work needed to be done by Global health agencies and world organizations such as WHO, CDC, UN, UNESCO, UNHCR others. Governments and health departments has to make useful health policies to implement in deadlines with serious accountability to AA Siddiqui [5] fight against any Epidemic or Pandemic (Figure 1,2).

Several clinical practice Ren [6] results showed that traditional Chinese medicine-TCM plays significant role in the treatment of COVID-19 bringing new hope for the prevention and control of COVID-19. TCM based on an over-all symptoms of 2019-nCoV pneumonia patients has suggested to prescribe prescription that are likely to be effective such as qingfei paidu decoction-QPD, gancaoganjiang decoction sheganmahuang decoction qingfei touxie fuzheng recipe, etc. QPD which consisted of Ephedrae Herba, Glycyrrhizae Radix et Rhizoma Praeprata cum Melle, Armeniacae Semen Amarum, Gypsum Fibrosum, Cinnamomi Ramulus, Alismatis Rhizoma, Polyporus, Atractylodis Macrocephalae Rhizoma, Poria, Bupleuri Radix, Scutellariae Radix, Pinelliae Rhizoma Praepratum cum Zingibere et Alumine, Zingiberis Rhizoma Recens, Asteris Radix et Rhizoma, Farfarae Flos, Belamcandae Rhizoma, Asari Radix et Rhizoma, Dioscoreae Rhizoma, Aurantii Fructus Immaturus, Citri Reticulatae Pericarpium, and Pogostemonis Herba, has been promoted as a general prescription in the diagnosis Ren [6] and treatment plan of COVID-19 in China.

Early diagnosis quarantine Pan [7] and supportive treatments are essential to cure patients. This paper reviews the literature on all available information about the epidemiology diagnosis isolation and treatments of COVID-19. Treatments including antiviral agents' chloroquine and hydroxychloroquine corticosteroids antibodies convalescent plasma transfusion and vaccines are discussed in this article. In addition, registered trials investigating treatment options for COVID-19 infection Pan [7] are listed.

Similar to outbreaks of Chan [8] other newly identified virus there is no proven regimen from conventional medicine and most reports managed the patients with lopinavir/ritonavir ribavirin, beta-interferon, glucocorticoid and supportive treatment with remdesivir undergoing clinical trial. In China Chinese medicine is proposed as a treatment option by national and provincial guidelines with substantial utilization. We reviewed the latest national and provincial clinical guidelines retrospective cohort studies and case series regarding the treatment Chan [8] of COVID-19 by add-on Chinese medicine.

A 34-year-old male returning Millán-Oñate [9] from Spain presented with complaints of fever and cough and class-II obesity being hospitalized. The respiratory viruses and bacteria tested by Film Array PCR were negative. Two days later clarithromycin was started because the patient was suspected as community-acquired pneumonia. At the third day the rRT-PCR confirmed the SARS-CoV-2 infection. A day later chloroquine was started because of that. His chest computed tomography was performed and showed bilateral multifocal ground-glass opacities with consolidation which suggested viral pneumonia as a differential diagnosis. Progressively his clinical condition improved and at day 9 patient rRT-PCR for
SARS-CoV-2 became negative. The patient was Millán-Oñate [9] discharged and isolated at home per 14 days.

\section{METHODS}

The Author of this Article has done Literature Review, Comparison and Critical analysis of more than 20 Published Articles and other reviews. Author has chosen the Comparative Literature review as methodology for this research article. The purpose is to show that Randomly chosen articles are in favor of availability of Prevention, Treatment and Vaccine development of COVID-19 as soon as possible to Treat the ill. SPSS 19 software is used to show Diagrammatic presentation for the results and analysis.

We found that infection is Giuseppe [10] transmitted from human to human and through contact with contaminated environmental surfaces. Hand hygiene is fundamental to prevent contamination. Wearing personal protective equipment is recommended in specific environments. The main symptoms of COVID-19 are fever cough, fatigue, slight dyspnea, sore throat, headache, conjunctivitis and gastrointestinal issues. Real-time PCR is used as a diagnostic tool using nasal swab tracheal aspirate or bronchoalveolar lavage samples. Computed tomography findings are important for both diagnosis and follow-up. To date, there is no evidence of any effective treatment for COVID-19. The main therapies being used to treat the disease are antiviral drugs chloroquine/hydroxychloroquine and respiratory therapy. Although many therapies have been proposed quarantine is the only intervention that appears Millán-Oñate [9] to be effective in decreasing the contagion rate.

Scientists have been trying Siddiqui [11] to understand the origin of COVID-19 and the virus that causes it SARS-CoV2. Originally scientists believed the virus may have developed in bats and later pangolins. However, genomic comparisons suggest that the SARS-Cov- 2 virus is the result of a recombination between two different viruses meaning the exact origin of the virus is still unclear. In the space of a few weeks we have all learned a lot Siddiqui [11] about COVID-19 and the virus that causes it SARS-CoV-2 (Table 1). Measure and statistical Analysis: IBM [12] IBM SPSS Software USA (Figure 3,4).

\section{RESULTS}

The SPSS Diagrammatic Presentation shows that firstly 13 Articles agreed $100 \%$ and 2 Articles did not, that there is urgent need of better Management and Treatment of COVID-19 novel corona virus. Second SPSS Diagram shows that All 15 Articles Favors the Importance of Urgent Recent Management and Treatment, Vaccine for the COVID-19 novel corona virus. There are some pictures, CT Scans and names of the Medicines involves in the Latest Treatment of the COVID-19 included in this Article.

The potential for combination Justin [13] therapy with baracitinib is high because of its low plasma protein binding and minimal interaction with CYP enzymes and drug transporters. Furthermore, there is the potential for combining baricitinib with the direct acting antivirals- lopinavir or ritonavir and remdesivir currently being used in the COVID-19 outbreak since it has a minimal interaction with the relevant CYP drug metabolizing enzymes. Combinations of baricitinib with these direct-acting antivirals could reduce viral infectivity viral replication and the aberrant host inflammatory response. This work demonstrates that the use of an AI-driven knowledge Justin [13] graph can facilitate rapid drug development. 
Table 1: 15 Randomly selected articles to show the importance of urgent recent management and treatment, vaccine for COVID-19 novel corona virus.

\begin{tabular}{|c|c|c|c|c|}
\hline S.NO & $\begin{array}{l}\text { Complete Reference of the } \\
\text { Articles selected for study }\end{array}$ & $\begin{array}{l}\text { Study Favors the } \\
\text { Importance of Urgent } \\
\text { Recent Management } \\
\text { and Treatment, Vaccine } \\
\text { for the COVID-19 Novel } \\
\text { Corona Virus. - YES }\end{array}$ & $\begin{array}{c}\text { Study Ignores the } \\
\text { Importance of Urgent } \\
\text { Recent Management } \\
\text { and Treatment, Vaccine } \\
\text { for the COVID-19 Novel } \\
\text { Corona Virus. -No }\end{array}$ & $\begin{array}{c}\text { Percentages } \% \text { of Articles } \\
\text { agreed the Importance of } \\
\text { Urgent Recent Management } \\
\text { and Treatment, Vaccine for } \\
\text { the COVID-19 Novel Corona } \\
\text { Virus }\end{array}$ \\
\hline 1 & $\begin{array}{l}\text { Serap Y, Serhat Ü (2020) Antiviral } \\
\text { treatment of COVID-19. Turkish } \\
\text { Journal of Medical Sciences 50(SI- } \\
\text { 1): 611-619. }\end{array}$ & YES & ------- & $100 \%$ \\
\hline 2 & $\begin{array}{c}\text { Jeroen Coumou, Peter Vries (2020) } \\
\text { Chloroquine as a possible treatment } \\
\text { for CoVID-19. Nederlands Tijdschr } \\
\text { Geneeskd 164: D4936. }\end{array}$ & YES & ------- & $100 \%$ \\
\hline 3 & $\begin{array}{l}\text { Rui Z, Xuebin W, Leng Ni (2020) } \\
\text { COVID-19: Melatonin as a Potential } \\
\text { Adjuvant Treatment. ELSEVIER Life } \\
\text { Sciences 250: } 117583 .\end{array}$ & YES & ------- & $100 \%$ \\
\hline 4 & $\begin{array}{c}\text { Binqing F, Xiaoling X, Haiming W } \\
(2020) \text { Why tocilizumab could Be } \\
\text { an effective treatment for severe } \\
\text { COVID-19? Journal of Translational } \\
\text { Medicine 18(1): } 164 .\end{array}$ & YES & ------- & $100 \%$ \\
\hline 5 & $\begin{array}{l}\text { Giuseppe Pascarella, Alessandro } \\
\text { Strumia, Chiara P (2020) COVID-19 } \\
\text { Diagnosis and Management: A } \\
\text { Comprehensive Review. WILEY, } \\
\text { Journal of Internal Medicine. }\end{array}$ & YES & ------- & $100 \%$ \\
\hline 6 & $\begin{array}{l}\text { Meo S, Klonoff D, Akram J } \\
\text { (2020) Efficacy of Chloroquine } \\
\text { and Hydroxychloroquine in } \\
\text { the Treatment of COVID-19. } \\
\text { European review of Medical and } \\
\text { Pharmacological Science 24(8): } \\
\text { 4539-4547. }\end{array}$ & YES & ------- & $100 \%$ \\
\hline 7 & $\begin{array}{c}\text { Mujeeb S, Olufemi A } \\
\text { (2020) Improving the } \\
\text { Efficacy of Chloroquine and } \\
\text { Hydroxychloroquine Against SARS- } \\
\text { CoV-2 May Require Zinc Additives } \\
\text { - A Better Synergy for Future } \\
\text { CoVID-19 Clinical Trials. Le Infizioni } \\
\text { in Medicina. 2020 Ahead of print } \\
\text { 28(2):192-197. }\end{array}$ & YES & ------- & $80 \%$ \\
\hline 8 & $\begin{array}{l}\text { Silvano E, Silvana N, Pasquale P } \\
\text { (2020) Update on treatment of } \\
\text { CoVID-19: Ongoing studies between } \\
\text { promising and disappointing } \\
\text { results. Le Infizioni in Medicina } \\
\text { 28(2): 198-211. }\end{array}$ & YES & ------- & $100 \%$ \\
\hline 9 & $\begin{array}{l}\text { Ahsan Ali Siddiqui (2020) True or } \\
\text { not? Chinese government quotes } \\
\text { WHO Chief statement "that there } \\
\text { is no Evidence that the New } \\
\text { Coronavirus Novel COVID } 19 \text { was } \\
\text { Produced in the Laboratory" But } \\
\text { US Government Says, that the } \\
\text { Coronavirus Originated from a } \\
\text { Laboratory in China despite the } \\
\text { Lack of Evidence. Biomed J Sci \& } \\
\text { Tech Res 27(5). }\end{array}$ & YES & ------ & $100 \%$ \\
\hline
\end{tabular}




\begin{tabular}{|c|c|c|c|c|}
\hline 10 & $\begin{array}{l}\text { Ahsan Siddiqui (2020) The } \\
\text { Epidemiology of COVID-19 Novel } \\
\text { Corona Virus to Possibly Control the } \\
\text { Disease and Other Factors Relating } \\
\text { to Health Around the World. Open } \\
\text { Acc J Bio Sci 2(2): 330-337. }\end{array}$ & YES & ------- & $100 \%$ \\
\hline 11 & $\begin{array}{l}\text { Ren JL, Zhang AH, Wang XJ } \\
\text { (2020) Traditional Chinese } \\
\text { medicine for COVID-19 treatment. } \\
\text { Pharmacological Research. 55: } \\
\text { 104743. }\end{array}$ & YES & ------- & $80 \%$ \\
\hline 12 & $\begin{array}{l}\text { Pan Z, Yanbing D, Xia W (2020) } \\
\text { The epidemiology, diagnosis } \\
\text { and treatment of COVID-19. } \\
\text { ELSEVIER, International } \\
\text { Journal of Antimicrobial Agents. } \\
\text { 55(5):105955. }\end{array}$ & YES & ------- & $100 \%$ \\
\hline 13 & $\begin{array}{l}\text { Chan KW, Wong VT, Tang SCW } \\
\text { (2020) COVID-19: An update } \\
\text { on the epidemiological, clinical, } \\
\text { preventive and therapeutic evidence } \\
\text { and guidelines of integrative } \\
\text { Chinese-Western medicine for } \\
\text { the management of } 2019 \text { novel } \\
\text { coronavirus disease. The American } \\
\text { Journal of Chinese Medicine } \\
48(3): 737-762 .\end{array}$ & YES & ------- & $100 \%$ \\
\hline 14 & $\begin{array}{l}\text { Millán-Oñate J, Millan W, Mendoza } \\
\text { LA, Sánchez CG (2020) Successful } \\
\text { recovery of COVID-19 pneumonia } \\
\text { in a patient from Colombia } \\
\text { after receiving chloroquine and } \\
\text { clarithromycin. Annals of Clinical } \\
\text { Microbiology and Antimicrobials } \\
\text { 19(1):16. }\end{array}$ & YES & ------ & $100 \%$ \\
\hline 15 & $\begin{array}{l}\text { Justin S, Anne P, Ivan G (2020) } \\
\text { COVID-19: Combining Antiviral and } \\
\text { Anti-Inflammatory Treatments. The } \\
\text { Lancet, Infectious Diseases 20(4): } \\
\text { 400-402. }\end{array}$ & YES & ------ & $100 \%$ \\
\hline
\end{tabular}

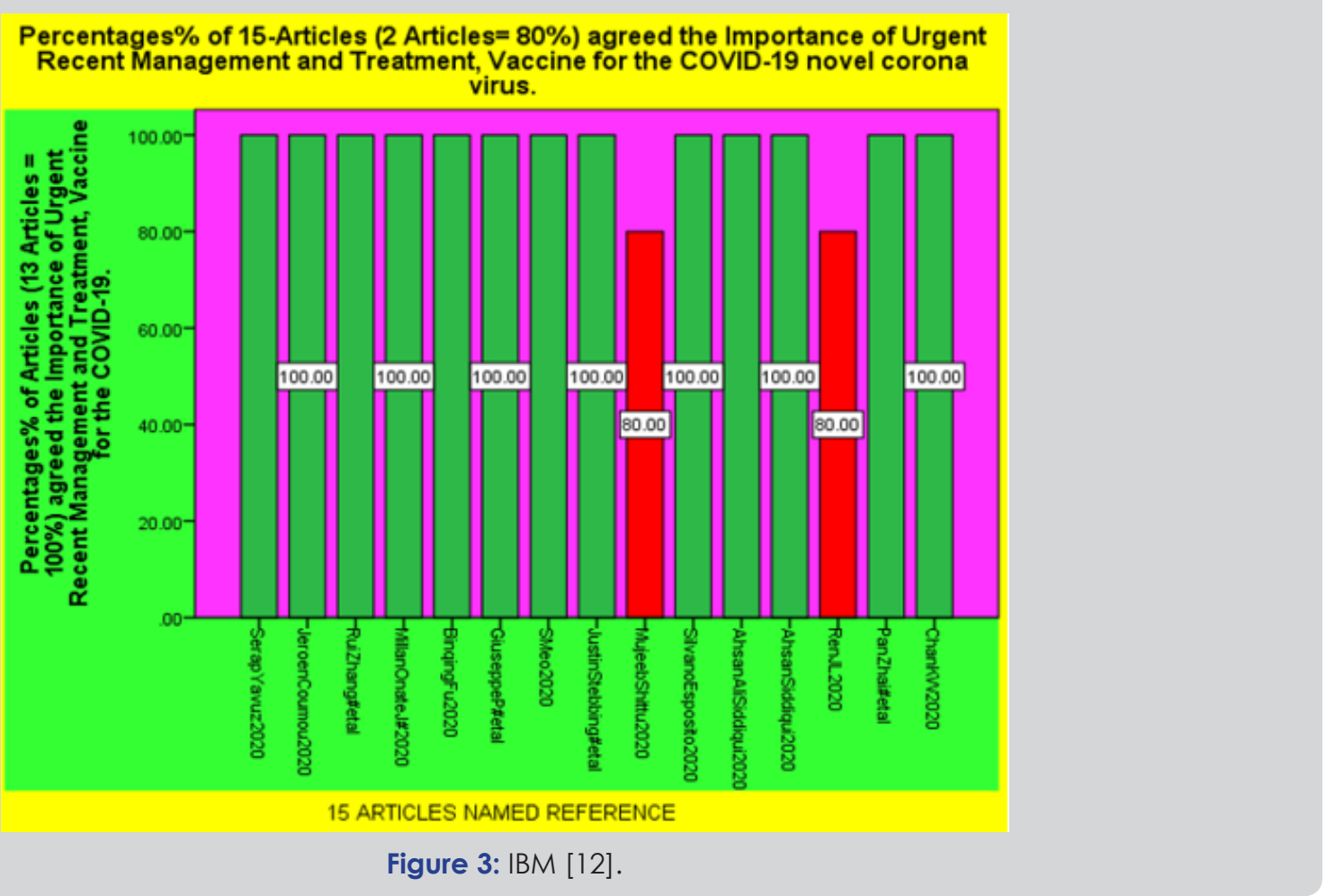




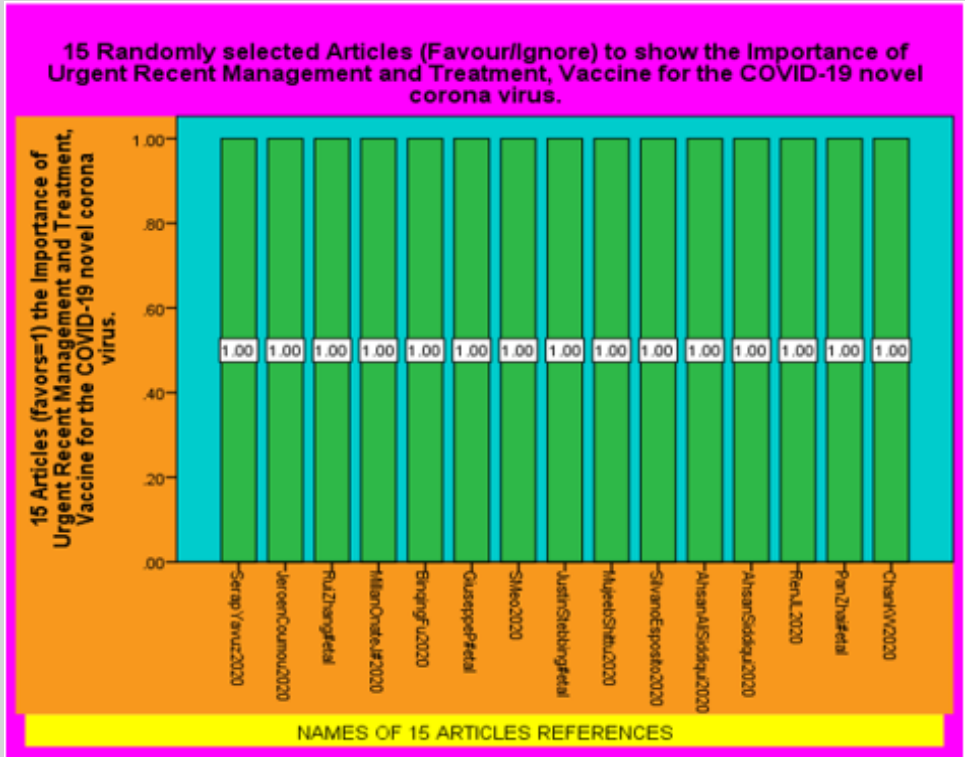

Figure 4: IBM [12].

There have been more than 300 clinical trials going on various antiviral and immunomodulating agents are in various stages of evaluation for COVID-19 in those trials and some of them will be published in the next couple of months. Despite the urgent need to find an effective antiviral treatment for COVID-19 through randomized controlled studies certain agents are being used all over the world based on either in-vitro or extrapolated evidence or observational studies. The most frequently used agents both in Turkey and all over the world including chloroquine hydroxychloroquine lopinavir/ritonavir, favipiravir and remdesivir will be reviewed here .Nitazoxanide and ivermectin were also included in this review as they have recently been reported to have an activity against SARS-CoV-2 in vitro and are licensed for the treatment of some other human infections.

In this study sequence Abdo [14] analysis modelling and docking are used to build a model for Wuhan COVID-19 RdRp. Additionally, the newly emerged Wuhan HCoV RdRp model is targeted by anti-polymerase drugs including the approved drugs Sofosbuvir and Ribavirin. The results suggest the effectiveness of Sofosbuvir IDX-184 Ribavirin and Remidisvir as potent drugs against the newly emerged $\mathrm{HCoV}$ disease. The present study presents a perfect model for COVID-19 RdRp enabling its testing in silico against anti-polymerase drugs. Besides, the study presents some drugs that previously proved its efficiency Abdo [14] against the newly emerged viral infection.

\section{DISCUSSION}

The COVID-19 pandemic Silvano [15] represents the greatest global public health crisis since the pandemic influenza outbreak of 1918. We are facing a new virus, so several antiviral agents previously used to treat other coronavirus infections such as SARS and MERS are being considered as the first potential candidates to treat COVID-19. Thus, several agents have been used by the beginning of the current outbreak in China first and all over the word successively as reported in several different guidelines and therapeutic recommendations. At the same time, a great number of clinical trials have been launched to investigate the potential efficacy therapies for COVID-19 highlighting the urgent need to get as Silvano [15] quickly as possible high-quality evidence (Figure $5,6)$.
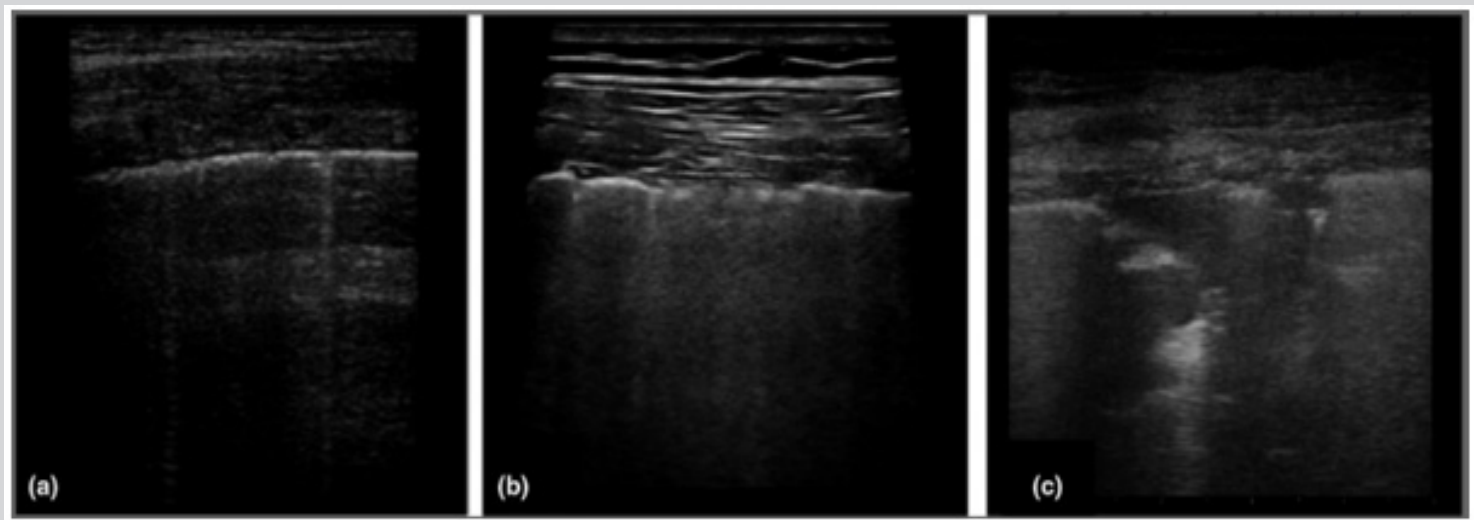

Figure 5: Patterns of COVID-19 at chest ultrasound. Early bilateral multifocal areas of interstitial syndrome. Interstitial pneumonia characterized by interstitial syndrome with B lines and preserved sliding sign. Advanced organized pneumonia with interstitial syndrome associated with multiple subpleural consolidations. 

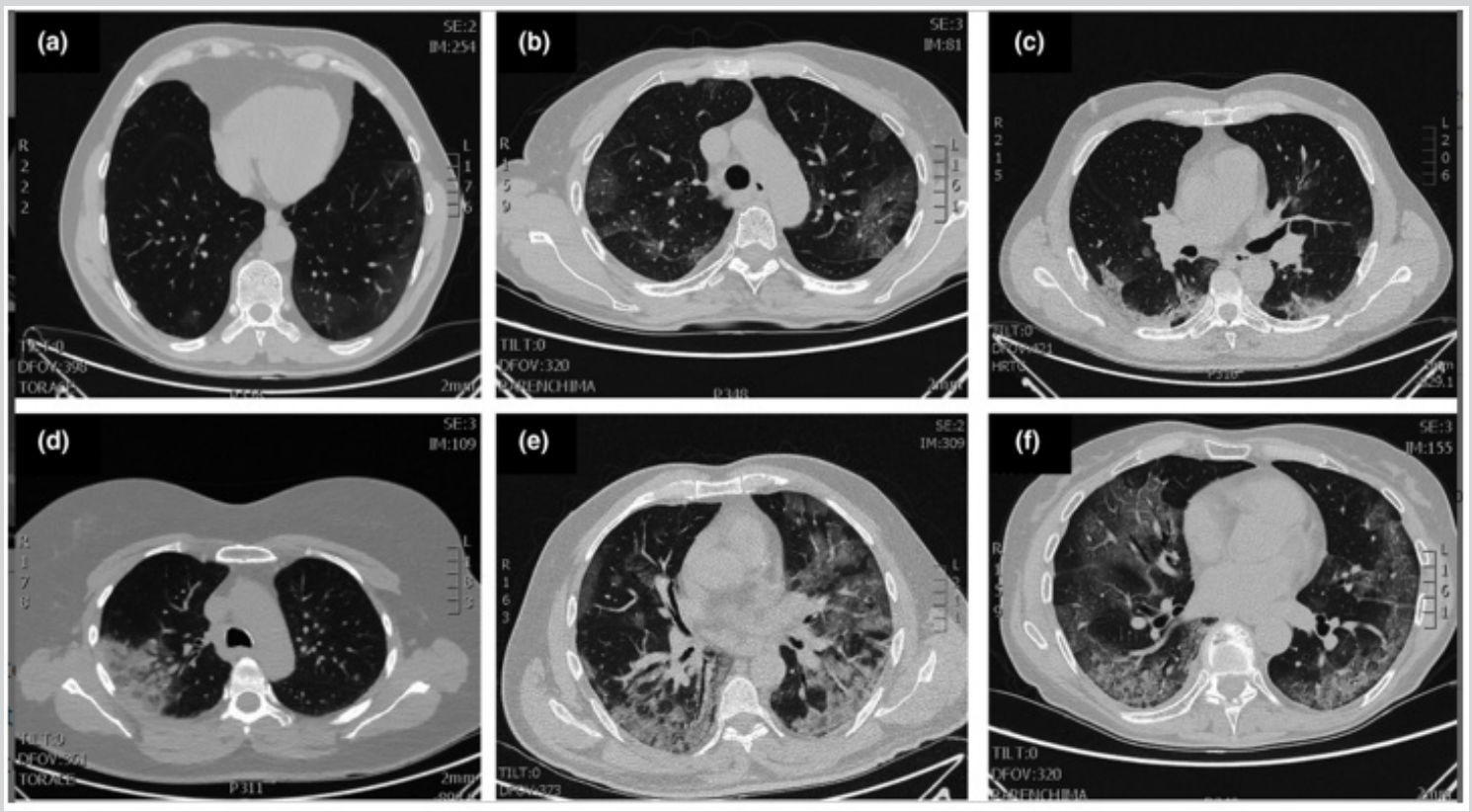

Figure 6: Typical patterns of COVID-19 at CT imaging. Ground glass shadows (early stage). Ground-glass opacities. Ground glass nodules and subpleural consolidation. Focal consolidation. Multifocal consolidation. Multifocal consolidation with honeycomb (end stage).

Chloroquine and hydroxychloroquine Meo [16] have antiviral characteristics in vitro. The findings support the hypothesis that these drugs have efficacy in the treatment of COVID-19. People are currently using these drugs for malaria. It is reasonable given the hypothetical benefit of these two drugs that they are now being tested in clinical trials to assess their effectiveness to combat this global health crisis. we identified a total of 09 published articles 03 clinical trials with sample size 150, 03 in vitro studies and 03 expert consensus reports. These studies were all suggestive that chloroquine and hydroxychloroquine can successfully treat COVID-19 infections. We found that COVID-19 infections are highly pandemic in countries where malaria is least pandemic and Meo [16] are least pandemic in nations where malaria is highly pandemic.

Four different influenza antiviral Ahsan [17] drugs amantadine, rimantadine, oseltamivir, and zanamivir are approved by the U.S. Food and Drug Administration-FDA for the treatment of influenza three are approved for prophylaxis. All four have activity against Ahsan [17] influenza A viruses. It is easy to implement the strategies and choose a program to reduce the incidence of T.B in Pakistan but the success in the NTP is not possible until the cooperation of the local community including youth elders men and women altogether in villages and cities.

This describes a model for TB control program which contains the essential components of a successful TB control program including three priority strategies for TB prevention and control, a) identifying and treating who have active TB, b) finding and screening persons who have had contact with TB patients to determine whether they are infected with Mycobacterium tuberculosis or have active TB providing appropriate treatment and c) screening populations at high risk for TB infection and development to isolate infected persons.

Several precautionary Mujeeb [18] measures have been prescribed to prevent further spread of the virus which include avoidance of social gatherings proper handwashing frequently disinfecting of used items and surfaces and so on. More recent studies have highlighted the possibility of treating patients infected with the novel SARS-CoV-2 virus with chloroquine and hydroxychloroquine of which mechanism of action is not completely understood. We seek to draw the attention of the scientific community to the possibility of drastically reducing the effects of the virus on the affected patients and improving clinical trials outcome through the synergistic action of zinc and Mujeeb [18] chloroquine in patients suffering from the coronavirus disease.

Human monoclonal antibody blocking S1 may play an important role in the immune prophylaxis of SARS. Fusion inhibitors reminiscent of enfuvirtide in the case of HIV may also be developed for SARS-CoV. Human interferons alpha- and beta-interferon as well as short interfering RNAs could further be pursued for the control of SARS. Various other compounds often with an ill-defined mode of action but selectivity indexes up to 100 have been reported to exhibit in vitro activity against SARS-CoV valinomycin, glycopeptide antibiotics, plant lectins, hesperetin, glycyrrhizin, aurintricarboxylic acid, chloroquine, niclosamide, nelfinavir and calpain inhibitors.

Preexposure prophylaxis and Oriol [19] postexposure prophylaxis-PEP with antimicrobial drugs are effective in preventing illness before potential exposure or after documented exposure to a variety of microbial pathogens and in reducing the risk of secondary spread of infection. For example, PEP with rifampicin is given to people exposed to index cases of invasive meningococcal infection and oseltamivir has been recommended by WHO for people at high risk of infection before or after exposure to pandemic influenza. The antimalarial drug hydroxychloroquine is licensed for the chemoprophylaxis and treatment of malaria and as a disease modifying antirheumatic drug Oriol [19].

The current evidence Mahmoud [20] impedes researchers from proposing an appropriate antiviral therapy against COVID-19 making the current situation a serious concern for international 
organizations such as World Health Organization (WHO). Only one clinical trial on the efficacy of antiviral therapy in management of COVID-19 was found. The results depicted that adding LopinavirRitonavir to the standard treatment regimen of patients with severe COVID-19 has no benefits. Moreover, 21 case-series and case-report studies reported the prescription of antiviral agents in COVID-19 none of which can be used to determine Mahmoud [20] the efficacy of antiviral therapies in confronting COVID-19 [21,22].

\section{CONCLUSION}

Current Pandemic of COVID-19 has taught all the Global Health authorities such as WHO, UN, UNESCO, UNICEF, UNHCR, EU Others and all Governments of 200 countries that we were not ready for COVID-19. Although Developed Countries such as USA, UK, France and countries of EU spends Billions of US Dollars on their Health System but it did not stop the Deaths of COVID-19 Pandemic in their countries and they are actually affected the most in this world. The reason is, there is no current Vaccine, proven Treatment for COVID-19 to this date and still research is going on to find the right Treatment or Vaccine for COVID-19. More hard work needed in Medical Sciences to find out the Proven and approved Vaccine and Treatment for current Pandemic or for preparation for Future Epidemics.

\section{REFERENCES}

1. Serap Y, Serhat Ü (2020) Antiviral treatment of COVID-19. Turkish Journal of Medical Sciences 50(SI-1): 611-619.

2. Jeroen C, Peter V (2020) Chloroquine as a possible treatment for COVID-19. Nederlands Tijdschr Geneeskd 164: D4936.

3. Rui Z, Xuebin W, Leng N (2020) COVID-19: Melatonin as a potential adjuvant treatment. ELSEVIER Life Sciences 250: 117583.

4. Binqing Fu, Xiaoling Xu, Haiming Wei (2020) Why Tocilizumab could be an effective treatment for severe COVID-19? Journal of Translational Medicine 18(1): 164.

5. Ahsan Ali Siddiqui (2020) True or not? Chinese government quotes WHO Chief statement "that there is no evidence that the new coronavirus novel COVID 19 was produced in the laboratory" But US government says, that the coronavirus originated from a laboratory in China despite the lack of evidence. Biomed J Sci \& Tech Res 27(5): 21148-21155.

6. Ren JL, Zhang AH, Wang XJ (2020) Traditional Chinese medicine for COVID-19 treatment. Pharmacological Research 39: 101165.

7. Pan Z, Yanbing D, Xia W (2020) The epidemiology, diagnosis and treatment of COVID-19. ELSEVIER, International Journal of Antimicrobial Agents 55(5): 105955.
8. Chan KW, Wong VT, Tang SCW (2020) COVID-19: An update on the epidemiological, clinical, preventive and therapeutic evidence and guidelines of integrative Chinese-Western medicine for the management of 2019 novel coronavirus disease. The American Journal of Chinese Medicine 48(3): 737-762.

9. Millán-Oñate J, Millan W, Mendoza LA, Sánchez CG (2020) Successful recovery of COVID-19 pneumonia in a patient from Colombia after receiving chloroquine and clarithromycin. Annals of Clinical Microbiology and Antimicrobials 19(1): 16.

10. Giuseppe P, Alessandro S, Chiara P (2020) COVID-19 diagnosis and management: A comprehensive review. WILEY, Journal of Internal Medicine.

11. A Siddiqui (2018) Critically review and evaluate national tuberculosis control program (NTP) of Pakistan. Journal of American Academic Research 6(3): 28-32.

12. IBM (2006) IBM SPSS Software USA.

13. Justin S, Anne P, Ivan G (2020) COVID-19: Combining antiviral and antiinflammatory treatments. The Lancet, Infectious Diseases 20(4): 400402 .

14. Abdo Elfiky (2020) Anti-HCV, nucleotide inhibitors, repurposing against COVID-19. Life Sciences Journal 248: 117477.

15. Silvano E, Silvana N, Pasquale P (2020) Update on treatment of COVID-19: Ongoing studies between promising and disappointing results. Le Infizioni in Medicina 28(2):198-211.

16. Meo S, Klonoff D, Akram J (2020) Efficacy of chloroquine and hydroxychloroquine in the treatment of COVID-19. European review of Medical and Pharmacological Science 24(8): 4539-4547.

17. Ahsan Siddiqui (2020) The epidemiology of COVID-19 novel corona virus to possibly control the disease and other factors relating to health around the world. Open Acc J Bio Sci 2(2): 330-337.

18. Mujeeb S, Olufemi A (2020) Improving the efficacy of chloroquine and hydroxychloroquine against SARS-CoV-2 may require zinc additives - A better synergy for future COVID-19 clinical trials. Le Infizioni in Medicina 28(2):192-197.

19. Oriol M, Bonaventura C (2020) Use of antiviral drugs to reduce COVID-19 transmission. The Lancet Global Health 8(5): e639-e640.

20. Mahmoud Y, Alireza Z, Kosar A (2020) Antiviral therapy in management of COVID-19: A systematic review on current evidence. Archives of Academic Emergency Medicin 8(1): e45.

21. Ahsan AS (2018) The global threat of bird (Avian) flu its treatment methods and public health preventive measures. SOJ Vet Sci 4(3): 1-4.

22. A Siddiqui (2018) Tuberculosis in adults in pakistan: Its epidemiology, preventive measures and current legislation. Journal of American Academic Research 6(3): 33-38. 